\title{
Vibrational spectroscopy as a confirmation method for structural analysis
}

\author{
A. S. Abdel-Rahman ${ }^{1}$, S. Kamal Abdel-Aal' ${ }^{1}$, Gyula Faigel $^{2}$, Katalin Kamaras ${ }^{2}$, Bortel Gábor ${ }^{2}$, Arron Pekker $^{2}$ \\ ${ }^{I}$ Physics department, Faculty of Science, Cairo University, Egypt; \\ ${ }_{2}^{2}$ Institute for Solid State Physics and Optics, Wigner Research Centre for Physics, Hungary; \\ asabry@sci.cu.edu.eg
}

In this work, the results obtained by single X-ray diffraction (XRD); even if for larger R-factor, are confirmed by another independent technique, one can study the vibrational spectroscopy with symmetry and group theory character tables. This method can be applied on the whole molecule or a part of it, mainly we search for function groups such as $\mathrm{H}_{2} \mathrm{O}$, an ionic part such as $\mathrm{NH}^{4+}$ or metal halide such as $\left(\mathrm{MnBr}_{\mathrm{x}}\right)$. The fine XRD data results five possible solutions for the same molecule with the same chemical formula, although the R-factor values are so close, this method can distinguish between these possible solutions upon the crystal structure. The study of $\mathrm{C}_{5} \mathrm{H}_{10}\left(\mathrm{NH}_{3}\right)_{2}\left(\mathrm{MnCl}_{4} \mathrm{Br}_{2}\right)$ results one solution of XRD is confirmed by IR and Raman spectroscopy.

The space group of the molecule Ima2 with $\mathrm{R}=3.33$, The $\left(\mathrm{MnCl}_{4} \mathrm{Br}_{2}\right)$ belongs to $\mathrm{D}_{4 \mathrm{~h}}$ of 5 Raman peaks and different 5 IR peaks.

The $\mathrm{Mn}_{2}\left(\mathrm{MnCl}_{4} \mathrm{Br}_{2}\right)$ is $\mathrm{C}_{2}, \mathrm{C}_{2 \mathrm{~h}}$ or $\mathrm{C}_{\mathrm{s}}$ according To the location of $\mathrm{Mn}$ atoms to the octahedral, the suitable solution is $\mathrm{C}_{2 \mathrm{~h}}$ which expects 12 IR and another 9 Raman peaks with good agreement with IR and Raman results.

1. J. R. Ferraro, "Low-Frequency Vibrations of Inorganic and Coordination Compounds", Plenum Press, New York (1971).

2. M. S. Dresselhaus G. Dresselhaus and A. Jorio. Group theory: Application to the physics of condensed matter (Springer, Berlin, Germany, 2008) CH8.

3. G. Herzberg. Molecular spectra \& molecular structure: II Infrared \& Raman spectra of polyatomic molecules (Von Nostrand Reinhold comp., New York, USA, 1945) pp. 462-487.

4. K. Kamaras, L. Badeeb, M. Özeren, A. Pekker, S. Abdel-Aal, A. S. Abdel-Rahman, P. Andricevic, L. Forro and E. Horvath, Bulletin of the American Physical Society, MARV20013K (2019).

5. S. K. Abdel-Aal, A. S. Abdel-Rahman, W. M. Gamal, M. Abdel-Kader, H. S. Ayoub, A. F. El-Sherif, M. Fawzy, S. Bozhko, E. E. Yakimov and E. B. Yakimov, Acta Crystallographica B75(5) 880-886 (2019).

Keywords: Vibrational, spectroscopy, group theory, character tables

Acta Cryst. (2021), A77, C956 